Review Article

\title{
Emotions at work and mental health: emerging directions
}

\author{
Janhavi Devdutt*, Seema Mehrotra
}

\begin{abstract}
Department of Clinical Psychology, National Institute of Mental Health and Neurosciences (NIMHANS), Bangalore, Karnataka, India
\end{abstract}

Received: 06 February 2018

Accepted: 06 March 2018

\section{*Correspondence:}

Ms. Janhavi Devdutt,

E-mail: janhavidevdutt@gmail.com

Copyright: (C) the author(s), publisher and licensee Medip Academy. This is an open-access article distributed under the terms of the Creative Commons Attribution Non-Commercial License, which permits unrestricted non-commercial use, distribution, and reproduction in any medium, provided the original work is properly cited.

\begin{abstract}
The present paper aims to present a brief overview of research on emotions at the workplace, and its relevance for mental health. Studies have been carried out linking emotions at work to various indices of well-being at work as well as to multiple health outcomes. The scope and utility of research focusing on day-to-day affective experiences is highlighted through studies using affective events theory as a guiding framework. There is a relative dearth of studies on emotion regulation processes at work, specifically on interpersonal regulation of emotions in work life as well as on regulation of positive emotions. Despite a boom in research on the magnitude of mental health issues at workplace and its wide-ranging implications, there is insufficient integration of research on emotions and mental health at work, with these two related strands of research evolving rather independently of each other. The overview points out areas of future research as well as implications for practice.
\end{abstract}

Keywords: Workplace emotions, Affective events theory, Emotion regulation, Mental health at work

\section{INTRODUCTION}

Work occupies a central role in the lives of individuals. Work is not only a source of economic well-being but also serves several socio-psychological functions. ${ }^{1}$ Employment is said to provide five categories of psychological experience that impact mental well-being, namely; time structure, social contact, collective effort and purpose, social identity and regular activity that helps in organizing one's daily life. ${ }^{2}$

\section{EMOTIONS AT WORK AND THEIR COR- RELATES}

Since work is one of the most important domains in one's life in contemporary societies, emotions experienced at work can have a wide range of implications. ${ }^{3}$ An extensive review of studies identified a range of ways in which affect influences critical organizational variables such as performance, decision making, turnover, prosocial behavior, negotiation, conflict resolution behavior, group dynamics, and leadership. ${ }^{4}$ Experience of strong emotions may lead to "intrusions", which compete for cognitive capacity and may interfere with performance. Excessive workload, lack of guidance and support, meeting deadlines, role dissatisfaction and ambiguity of job description are just a few examples of the antecedents of negative emotions at work that have been examined. ${ }^{5}$ Although (mild) negative affect may sometimes be associated with positive consequences, positive mood is a more likely source of positive impact on social interactions, helping behavior, creativity, decision making, and dealing with difficult situations. ${ }^{6,3}$ The outcomes of emotions experienced at work are not uniform and depend on a variety of personal and contextual characteristics. ${ }^{6}$

Emotional experiences at work have been linked to various indices of well-being at work. Job satisfaction, a measure of the employee's evaluation of the job, is one of the most frequently studied indices of work-related subjective well-being. Job satisfaction has often been 
used as a proxy for employee well-being at work. ${ }^{7}$ Affective well-being at work classifies work-related emotions into two dimensions: pleasure and activation. ${ }^{8}$ Four quadrants result from the combination of the two axes: anxiety (high activation and low pleasure), enthusiasm (high activation and high pleasure), depression (low activation and low pleasure), and comfort (low activation and high pleasure). ${ }^{9}$ Work engagement is yet another index that has emerged as a popular variable in organizational research. It is defined as a positive, fulfilling, work-related state of mind that is characterized by vigor, dedication, and absorption. ${ }^{10}$ Available research indicates that job resources such as social support from colleagues, performance feedback, skill variety, autonomy, and learning opportunities are positively associated with work engagement. ${ }^{11}$ Personal resources such as self-esteem, self-efficacy, locus of control, and emotion perception and regulation skills are also positive predictors of work engagement. ${ }^{11}$ Engaged employees (1) frequently experience positive emotions; (2) experience better psychological and physical health; (3) create their own job and personal resources (e.g., support from others); and (4) transfer their engagement to others. $^{12}$ In the longer term, emotions have also been related to health consequences. ${ }^{13}$ For example, anger mediates between perceptions of injustice and retaliatory behavior, and is related to health consequences such as coronary heart disease. ${ }^{13}$

The study of emotions at workplace assumes importance in the larger context of mental health of employees. It is estimated that $15-30 \%$ of workers experience some form of mental health problem during their working lives. ${ }^{2}$ Work related stress and its negative mental health outcomes, especially common mental health disorders like depression and anxiety, have been extensively studied. ${ }^{14,15}$ Severity of major depressive disorder is seen to be significantly associated with treatment usage/costs, unemployment and reduced work performance. ${ }^{16}$ Many studies on workplace interventions are targeted at helping individuals already identified as having mental health problems to enter, sustain or return to employment. ${ }^{17}$

While bulk of the available research has focused on negative affect and associated negative outcomes; broaden and build theory has provided an impetus to an examination of the role of positive emotions at work. ${ }^{18}$ Application of broaden and build theory to the work setting suggests that when employees experience positive events at work, they generate new ideas, additional resources, better social relationships, and show improved problem solving via recognition of a wider scope of possible solutions, thereby reducing stress. ${ }^{19}$ Working in a climate of trust and respect can build relational resources via more positive day-to-day interactions, which, in turn, lead to behaviors that support self-determination and autonomy. ${ }^{20}$ Results of a series of experience sampling studies suggested that daily positive events are associated with increased self-esteem and perceived control. ${ }^{21,22}$ Despite its vast scope for understanding the employee performance and well-being, the experience and regulation of positive emotions and their correlates have been infrequently examined in the context of work.

\section{STUDY OF AFFECTIVE EVENTS AT WORK}

Although the experience of work is saturated with emotion, research has relatively neglected the impact of everyday emotions on organizational life. Research has often been confined to: (1) a limited set of relatively generalized and stable affective states like satisfaction, stress, mood and certain aspects of commitment, and (2) the role of emotions when encountering discrete, critical/major events, such as organizational change, role transitions, and intergroup conflict. ${ }^{23}$ Moreover these constructs have been assessed using structured questionnaires, relatively ignoring, qualitative methods to capture day-to-day affective experiences and their regulation at work. ${ }^{7}$ Most research on emotions in the workplace has focused on stress or job satisfaction, assuming negative emotional states as mediators of such generalized reaction tendencies. ${ }^{13}$ Also, the correlates of positive emotions and their regulation at work are yet to be sufficiently examined. Very little attention has been given to studies that evaluate the components and effectiveness of positive mental health interventions at workplace. $^{17}$

Affective events theory (AET) has provided a useful framework for studying emotions, moods and job satisfaction at work. ${ }^{24}$ According to AET, an emotional response flows from a particular type of event labeled as an affective event. These affective events are shaped by the environment in which interactions occur. The emotions that flow from affective events are in part a consequence of the event and in part a consequence of individual factors that shape the interpretation of the event. These emotions, in turn, impact the individuals' attitudes and behaviour. Several studies are being carried out to test the predictions based on AET. In an investigation of the proposed paths of the affective events theory, the use of an index comprising of overall emotional experiences, a composite of the intensity of emotional experience at work across the number of events reported was recommended. ${ }^{25}$ Negative emotions experienced at work over 2 weeks were significantly predictive of intentions to leave the job. Sadness emotions over 2 weeks predicted work attitudes beyond trait affectivity. However, positive affectivity's relationship with work attitudes was not mediated by emotional reactions at work. Another study explored which affective events at work were associated with which kind of emotions and constructed an eventemotion matrix for both positive and negative affect. ${ }^{26}$ Researchers have posited that day to day fluctuations in work engagement could be predicted by work events and emotions experienced. While the impact of positive events on engagement was influenced by trait positive affect, social support buffered the impact of negative events at work. ${ }^{27}$ The interplay of negative and positive 
affect has been considered to play an important role in work engagement. ${ }^{28}$ Experience of pleasant affective states, has been linked to several organizational outcomes such as increased job satisfaction, organizational commitment, and organizational citizenship behavior. ${ }^{29}$ In yet another study using experience sampling methodology, interpersonal interaction characteristics influenced job satisfaction through the mediating role of affective states. $^{30}$ Moreover, positive affective states buffered the detrimental association between negative affect and job satisfaction. Dynamic interaction between the person and the environment are considered important in the AET framework, however there is relative paucity of research that examines the role of emotion regulation processes using the AET framework.

\section{EMOTION REGULATION PROCESSES WORK}

A process analysis of AET was carried out to understand how, when and why stimuli/events at work trigger emotions and moods which in turn influence cognitive and behavioral outcomes at work. ${ }^{31}$ In their analysis the authors discussed the linkages between affective events and consequences by the processes of perception, assimilation, understanding, and emotion management.

A study using the day reconstruction method found evidence supporting predictions of AET and reported that use of emotion focused coping at work that aimed at managing emotions (rather than resolving or prolonging events associated with these emotions) could have beneficial short term consequence on task performance for employees. ${ }^{32}$ The need for research on various kinds of hedonic and instrumental motives that underlie emotional regulation and the utility of examining emotional regulation as a motivated process have also been discussed. $^{33}$

Very often, affect regulation is conceptualized and examined as an intrapersonal process. But researchers interested in emotions are increasingly recognizing that emotions are social in nature, and serve various interpersonal functions such as communication. ${ }^{34} \mathrm{~A}$ significant proportion of emotional work events may be shared with coworkers in one way or another. Group norms, behaviors of the leaders and coworker responsiveness play a role in influencing whether and which events are shared. Disclosure of emotion events tends to be often associated with the motive of mitigating negative emotions and capitalization of positive emotions. Research concerning the management of other people's affect or utilization of interpersonal resources at work for managing one's own emotions at work is still in its infancy. Interpersonal affect regulation has been defined as the deliberate and socially induced initiation, maintenance or modification of the occurrence, intensity, or duration of feeling states. ${ }^{34}$ Effective management of others' negative emotions in the workplace may be essential in contexts such as customer/client relationships, organizational change, performance feedback, teamwork, and leader-follower relationships. ${ }^{35}$

The interpersonal emotion management (IEM) scale focuses on managing negative emotions in others. It has been found that strategies used in self emotion regulation (e.g. reappraisal, representing antecedent focus strategies, and suppression) are associated with similar strategies used for interpersonal emotional regulation. ${ }^{35} \mathrm{~A}$ theoretical framework with three dimensions of motivations for interpersonal emotion regulation at work has been proposed. ${ }^{36}$ These are expressed in terms of the extent to which regulation is motivated by autonomy (intrinsic vs. extrinsic), relatedness (prosocial vs. egoistic), and competence (performance- vs. pleasureoriented) needs. Combining these dimensions eight possible categories of motives underlying interpersonal emotion regulation have been suggested (coaching motive, instrumentality motives, compassion motives, hedonism motives, emotional labour motives, conformity motives, impression management motives and identity construction motives).

Emotion regulation of self and others scale attempts to capture intrinsic or extrinsic regulation (target being one's own or others' affect, along with affect-improving or worsening goals). ${ }^{37}$ This has been critiqued by researchers for weak empirical evidence especially for affect worsening goals. ${ }^{38} \mathrm{~A}$ focus on interpersonal affect regulation in terms of how individuals use various strategies to regulate their own emotions through others has been proposed. A measure of interpersonal affect regulation has been developed. This measure contains four factor-based subscales: enhancing positive affect, soothing, perspective taking and social modeling. The need to consider the role of cultural context that can shape the nature of interpersonal processes, including interpersonal emotional regulation as well as the need for studies that explore the complex interactions between intrapersonal and interpersonal affect regulation has been highlighted.

Several researchers have pointed out how emotions at workplace have tended to largely focus on emotional labor which is to do with the regulation of emotions in the context of interaction with clients in the service of organizational goals. ${ }^{34}$ Research literature has highlighted the relative neglect of studies focusing on emotion-work that is entailed in meeting organizational goals in the context of interactions with organizational insiders such as co-workers. ${ }^{39}$ It has been suggested that a comprehensive model of emotion regulation at work should include both emotion labour and emotion-work. The differences between interactions with clients (typically short-lasting) and those with co-workers (typically longer-term and evolving over time) also necessitate examining them separately.

Emotion management at work needs to be examined not just from organizational/professional rules of 
conduct/prescribed displays or from commercial perspective but also in accordance with general social feeling rules that affect organizational life. ${ }^{40}$ In other words, all emotional regulation processes seen at work may not be classifiable as emotion labor. Unfortunately, everyday workplace emotions and their regulation that naturally occur at work have been examined less often than emotional displays and emotion regulation as prescribed by the organizations/in the service of organizational goals. Interpersonal affect regulation has been most often studied in the leader-follower or customer-employee relationships and less often in the context of relationships with co-workers. ${ }^{41-43}$ A recent review has identified four broad approaches to research work on interpersonal emotional regulation: (1) as a purely extrinsic process (i.e. only others' emotions are regulated); (2) as a differentiation between the extrinsic interpersonal emotional regulation process and the intrinsic individual emotion regulation process; (3) as cooccurring intrinsic and extrinsic interpersonal processes; or (4) as the interpersonal co-regulation of emotion, where interaction participants actively and dynamically regulate their own and each other's emotional experiences and expressions. $^{44}$

As far as the Indian scenario is concerned, a scan of the published Indian research shows that bulk of research in this area has focused on the constructs of emotional intelligence and emotion labour. ${ }^{45,46}$ There are a few studies that have utilized the affect events theory as a framework. $^{47,48}$ However there is scarcity of studies on day-to-day affective events as well as intrapersonal and interpersonal emotional regulation processes at work as well as their mental health correlates.

\section{EMOTION REGULATION AND MENTAL HEALTH AT WORK}

Disturbances/deficits in emotion regulation are core features of many emotional disorders that are seen in mental health settings. ${ }^{49}$ As individuals spend a large part of their adulthood at workplaces it is therefore important to address this issue in the context of workplace settings. There is a need for integration of research on mental health at workplace and that on emotions in organizational life, as these two strands of research are evolving somewhat independently. This is similar to the need for integrating emotion regulation and emotional intelligence as two research traditions. ${ }^{50}$ Moreover, research in the field of mental health at work has focused mostly on negative moods and their regulation via intrapersonal processes. However, newer research suggests that dysregulation of positive emotions in emotional disorders also requires examination. Emergent research highlights the need to study interpersonal aspects of emotion regulation. ${ }^{44}$ Often, individuals present to clinical settings with psychological distress that is manifest in the context of their work-life and is linked to issues related to difficulties in intrapersonal as well as interpersonal affect regulation at work. A contextualized exploration of emotion regulation processes can help in an in-depth and nuanced understanding that has utility in psychological interventions. Hofmann described the limitations of sole reliance on intrapersonal emotion regulation and described interpersonal emotional regulation in mood and anxiety disorders. ${ }^{51}$

An international review of guidelines on workplace mental health revealed that these did not focus on prevention but were mostly restricted to detection and treatment of mental health problems at workplace. ${ }^{17}$ Research on intrapersonal and interpersonal emotion regulation processes at work in individuals with common mental disorders can also help in development of peer support interventions for people in distress. In addition, research on spontaneously occurring interpersonal emotional regulation processes with coworkers and leaders can pave way for development of preventive programs that aim at building a supportive work environment for fostering well-being and productivity.

\section{CONCLUSION}

Research on emotions in organizations has certainly gained impetus in the last three decades. Research into the dynamic processes at work that give rise to day-today affective events in different cultures, emotional reactions to such events and factors influencing regulation of positive and negative emotions at work forms a fruitful area of further inquiry. There is also a heightened recognition of the need to attend to mental health issues of individuals at work as well as the potential role of work environment and related variables on well-being of individuals. However, there is a need for studies that facilitate understanding the interface between mental health at work and workplace emotions.

\section{Funding: No funding sources \\ Conflict of interest: None declared \\ Ethical approval: Not required}

\section{REFERENCES}

1. Harpaz I. The meaning of work in Israel: Its nature and consequences. New York, NY: Praeger; 1990.

2. Harnois G, Gabriel P, World Health Organization. Mental health and work: impact, issues and good practices; 2000. Available at http://digitalcommons. ilr.cornell.edu/gladnetcollect/222/. Accessed on 1 June, 2017.

3. Brief AP, Weiss HM. Organizational behavior: Affect in the workplace. Annu Rev Psychol. 2002;53(1):279-307.

4. Barsade SG, Gibson DE. Why does affect matter in organizations? Acad Manag Perspect. 2007;21(1):36-59.

5. Boateng IA, Agyei A. Employee's Emotions: A Manageable Weapon for Organizations. Int J Hum Resource Stud. 2013;3(4):256-67. 
6. Forgas JP. Affective influences on interpersonal behavior. Psychol In. 2002;3(1):1-28.

7. Grandey AA. Emotional regulation in the workplace: A new way to conceptualize emotional labor. J Occup Health Psychol. 2000;5(1):95-110.

8. Warr PB. The measurement of well-being and other aspects of mental health. J Occup Health Psychol. 1990;63(3):193-210.

9. Gonçalves SP, Neves J. Factorial validation of Warr's (1990) well-being measure: A sample study on police officers. Psychol. 2011;2(7):706-12.

10. Schaufeli WB, Salanova M, González-Romá V, Bakker AB. The measurement of engagement and burnout: A two sample confirmatory factor analytic approach. J Happiness Stud. 2002;3(1):71-92.

11. Albrecht SL. (Ed.). Handbook of employee engagement: Perspectives, issues, research and practice. Glos, England: Edward Elgar; 2010

12. Bakker AB, Schaufeli WB, Leiter MP, Taris TW. Work engagement: An emerging concept in occupational health psychology. Work Stress. 2008;22(3):187-200.

13. Semmer NK, McGrath JE, Beehr TA. Conceptual issues in research on stress and health. In: Cooper CL, ed. Handbook of Stress and Health. 2nd ed. New York: CRC Press; 2005: 1- 43.

14. Kulkarni GK. Burnout. Indian J Occup Environ Med. 2006;10(1):3-4.

15. Rao JV, Chandraiah K. Occupational stress, mental health and coping among information technology professionals. Indian $\mathbf{J}$ Occup Environ Med. 2012;16(1):22-6.

16. Birnbaum HG, Kessler RC, Kelley D, Ben-Hamadi R, Joish VN, Greenberg PE. Employer burden of mild, moderate, and severe major depressive disorder: mental health services utilization and costs, and work performance. Depress Anxiety. 2010;27(1):78-89.

17. Mcdaid D, Park AL. Investing in mental health and well-being: findings from the DataPrev project. Health Promot Int. 2011;26(Suppl 1):108-39.

18. Fredrickson B. The role of positive emotion in positive psychology: The broaden-and-build theory of positive emotion. Am Psychol. 2001;56(3):21826.

19. Bono JE, Glomb TM, Shen W, Kim E, Koch AJ. Building positive resources: Effects of positive events and positive reflection on work stress and health. Acad Manag J. 2013;56(6):1601-27.

20. Spreitzer G, Sutcliffe K, Dutton J, Sonenshein S, Grant AM. A socially embedded model of thriving at work. Organ Sci. 2005;16(5):537-49.

21. Nezlek JB, Plesko RM. Day-to-day relationships among self-concept clarity, self-esteem, daily events, and mood. Pers. Soc. Psychol. Bull. 2001;27(2):201-11.

22. Reis HT, Gable SL. Toward a positive psychology of relationships. In: Keyes CLM, Haidt J, eds. Flourishing: Positive Psychology and the Life Well- lived. Washington, DC, US: American Psychological Association: 2003: 129-159.

23. Ashforth BE, Humphrey RH. Emotion in the workplace: A reappraisal. Hum Relat. 1995;48(2):97-125.

24. Weiss HM, Cropanzano R. Affective events theory: A theoretical discussion of the structure, causes and consequences of affective experiences at work. In: Staw BM, Cummings LL, eds. Research in organizational behavior. Greenwich, CT: JAI Press; 1996: 1-74.

25. GrandeyAA., Tam AP, Brauburger AL. Affective states and traits in the workplace: Diary and survey data from young workers. Motiv Emot. 2002;26(1):31-55.

26. Basch J, Fisher C. Affective events-emotions matrix: A classification of work events and associated emotions. In: Ashkenasy N, Hartel C, Zerbe W, eds. Emotions in the Workplace: Theory, Research and Practice. Westport, CT: Quorum Books; 2000: 36-49.

27. Bledow R, Schmitt A. Work engagement as a dynamic process: The interplay between events, emotions, and resources. In Poster presented at the 2008 Conference of the Society of Industrial and Organizational Psychology, San Francisco, CA 2008. Available at http://www.evidence-basedentrepreneurship.com/content/publications/376.pdf. Accessed 27 January, 2018.

28. Bakker AB. Daily fluctuations in work engagement. Eur Psychol. 2014;19(4):227-36.

29. Erol-Korkmaz HT, Sumer HC. Relations of Work Events, Core Self and External Evaluations, and Affective State with Employee Attitude and Behavior. Int J Bus Soc Sci. 2012;3(22):137-50

30. Dimotakis N, Scott BA, Koopman J. An experience sampling investigation of workplace interactions, affective states, and employee well-being. J Organ Behav. 2011;32(4):572-88.

31. Ashton-James CE, Ashkanasy NM. Affective Events Theory: a strategic perspective. In: Zerbe WJ, Hartel CEJ, Ashkanasy NM, ed. Research on Emotion on Organizations. Volume 4: Emotions, Ethics, and Decision-Making. Bingley, UK: Emerald Group Publishing/JAI Press; 2008: 1-34.

32. Gooty J, Gavin MB, Ashkanasy NM, Thomas JS. The wisdom of letting go and performance: The moderating role of emotional intelligence and discrete emotions. J Occup Organ Psychol. 2014;87(2):392-413.

33. Tamir M. Why do people regulate their emotions? A taxonomy of motives in emotion regulation. Pers Soc Psychol Rev. 2016;20(3):199-222.

34. Niven K, Totterdell P, Holman, D. Affect regulation and well-being in the workplace: an interpersonal perspective. In: Antoniou A, Cooper C, Chrousos, G, Spielberger C, Eysenck M. eds. Handbook of Managerial Behavior and Occupational Health. Cheltenham, UK: Edward Elgar; 2009: 218-228. 
35. Little LM, Kluemper D, Nelson DL, Gooty J. Development and validation of the interpersonal emotion management scale. J Occup Organ Psychol. 2012;85(2):407-20.

36. Niven K. Why do people engage in interpersonal emotion regulation at work? Organ Psychol Rev. 2015;6(4):305-23.

37. Niven K, Totterdell P, Stride CB, Holman D. Emotion Regulation of Others and Self (EROS): The development and validation of a new individual difference measure. Curr Psychol. 2011;30(1):5373.

38. Hofmann SG, Carpenter JK, Curtiss J. Interpersonal emotion regulation questionnaire (IERQ): Scale development and psychometric characteristics. Cogn Ther Res. 2016;40(3):341-56.

39. Leighton CL. Workplace Emotion Regulation: Making the Case for Emotional Labour and Emotion Work. Doctoral dissertation, University of Western Australia; 2012. Available at researchrepository.uwa.edu.au/files/3227418/Leighton_Cath erine_Lee_2012.pdf. Accessed on 3 January, 2018.

40. Bolton SC. Emotion Management in the Workplace. Palgrave Macmillan; 2005.

41. Brown FW, Moshavi D. Transformational leadership and emotional intelligence: A potential pathway for an increased understanding of interpersonal influence. $\mathrm{J}$ Organ Behav. 2005;26(7):867-71.

42. Cross R, Parker A. Charged up: Creating energy in organisations. J Organ Excell. 2004;23(4): 3-14.

43. Lee S, Dubinsky AJ. Influence of salesperson characteristics and customer emotion on retail dyadic relationships. Int Rev Retail, Distribution Consumer Res. 2003;13(1):21-36.

44. Troth AC, Lawrence SA, Jordan PJ, Ashkanasy NM. Interpersonal Emotion Regulation in the
Workplace: A Conceptual and Operational Review and Future Research Agenda. Int J Manag Rev. 2017.

45. Pachauri V, Bharti V. Emotional Intelligence and its impact on job satisfaction. J Manag Value Ethics; 2015; 5(2):36-44.

46. Soni S. Workplace Emotions: A Study of Frontline Hotel Employees. Manag Labour Stud. 2017;42(3):237-52.

47. Goswami A, Nair P, Beehr T, Grossenbacher M. The relationship of leaders' humor and employees' work engagement mediated by positive emotions. Leadersh Organ Dev J. 2016;37(8):1083-99.

48. Subba D, Rao MK. Measuring the Effects of CSR on Compassion at Workplace : An Empirical Study in North East Region of India. Purushartha: J Manag Ethics Spiritual. 2016;9(1):26-42.

49. Aldao A, Nolen-Hoeksema S, Schweizer S. Emotion-regulation strategies across psychopathology: A meta-analytic review. Clin Psychol Rev. 2010;30(2): 217-37.

50. Peña-Sarrionandia A, Mikolajczak M, Gross JJ. Integrating emotion regulation and emotional intelligence traditions: a meta-analysis. Front Psychol. 2015;6:160.

51. Hofmann SG. Interpersonal emotion regulation model of mood and anxiety disorders. Cogn Ther Res. 2014;38(5):483-92.

Cite this article as: Devdutt $\mathrm{J}$, Mehrotra S. Emotions at work and mental health: emerging directions. Int $\mathbf{J}$ Community Med Public Health 2018;5:1233-8. 